\title{
On the Integrity of Science: The Issues Since Bronowski
}

\section{Citation}

Holton, Gerald. 1985. On the Integrity of Science: The Issues Since Bronowski. Leonardo 18 (4), Special Issue: Jacob Bronowski: A Retrospective (1985): 229-232.

\section{Permanent link}

http://nrs.harvard.edu/urn-3:HUL.InstRepos:37903226

\section{Terms of Use}

This article was downloaded from Harvard University's DASH repository, and is made available under the terms and conditions applicable to Other Posted Material, as set forth at http:// nrs.harvard.edu/urn-3:HUL.InstRepos:dash.current.terms-of-use\#LAA

\section{Share Your Story}

The Harvard community has made this article openly available.

Please share how this access benefits you. Submit a story.

\section{Accessibility}




\title{
On the Integrity of Science: The Issues Since Bronowski
}

\author{
Gerald Holton
}

\begin{abstract}
A fulcrum for much of Jacob Bronowski's writing was his conception of the integrity of science. A reading of his work, and particularly his 1956 essay "The Educated Man in 1984", allows one to resolve this conception into five components, each relevant today.
\end{abstract}

Jacob Bronowski was a mathematician, a historian of ideas, an inventor, an administrator, a poet, a literary critic, a philosopher of science and an elegant stylist. But he was above all the eloquent missionary on behalf of a coherent modern world view. Someone made the useful distinction between 'splitters' and 'lumpers'. Despite his varied talents and achievements, Bronowski was not a splitter: like all people of great influence, he knew how to pull together a multiplicity of elements in the service of one cause. His main underlying concern was the relationship between modern science and modern man. Within this vast topic, his focus was on the integrity of science.

Before I define Bronowski's five-fold conception of the integrity of science, let me stress another remarkable and idiosyncratic property of his writings. His vision of the integrity of science, at once simple in its main outline and complex in detail, is always implicit, and often explicit, in almost every essay or chapter he wrote. Therefore one can reconstruct with tolerable fidelity the essence of his view from any portion of his total opus. Bronowski not only celebrated what he called "a sense of unity with the world, the happy passion which fires the scientist and the painter" [1], he exemplified it in two different ways-in what he said and again in how he said it. This two-fold unity can be found in any of his works, such as The Common Sense of Science,

Gerald Holton (physicist, science historian, educator), Department of Physics, Jefferson Physical Laboratory, Harvard University, Cambridge, MA 02138, U.S.A

Based upon a presentation given at the Symposium "Jacob Bronowski: A Retrospective" held by NEXA, the Science-Humanities Convergence Program at San Francisco State University, June 1984, in conjunction with the Pacific Regional Meeting of the American Association for the Advancement of Science, funded by the Walter and Elise Haas Fund, San Francisco, CA.

Copyright of the author. Reprinted by permission.
Science and Human Values, The Ascent of Man [2], and The Identity of Man.

Bronowski's essay "The Educated Man in 1984" [3] was published in 1956, before Sputnik made education a subject of national concern, as it has become once again. We should look at the essay today because Bronowski did not make predictions lightly, and he would undoubtedly have felt obliged to check on his own prophecies.

When he was writing this essay 28 years ago, Bronowski was not optimistically looking forward to 1984 . He thought ours might by now have become a world run by a small cadre of technically knowledgeable specialists ruling the masses whose scientific ignorance made them powerless. That, in his words, would be a slave world. He believed that, without the universal diffusion of specific skills and rational attitudes that science can teach, no nation could call itself modern. As he put it, "A nation in which the fuse box is still handled with suspicion is today a backward nation" [4]. So would be a nation in which an intelligent person does not "know in his bones the difference between a million and ten" [5], where he cannot handle the problems of scale and orders of magnitude, where the essentials of probability and statistics are not part of everyone's education. In a democracy, such a "lack cripples the citizen's judgment in the modern world" [6]. Thereby the bulk of the population would be "abdicating [its] share of the future, and walking with open eyes towards slavery ... There is only one way to head off such a disaster, and that is to make the educated man universal in 1984" [7].

These sentences imply two related senses of the conception of the integrity of science. First, a lack of scientific understanding endangers one's own integrity as a functioning person and as a citizen. Second, without every person having that kind of integrity, the integrity of a democracy is at risk. Neither of these ideas was common in 1956; if they are now more widely accepted, it is perhaps because of pioneers such as Bronowski himself.

The difficulty of achieving such twofold integrity is far greater than Bronowski foresaw. For Bronowski did not dare to imagine the possibility at this point in our history that in political decisions the governing elite itself-not excluding the technocrats-would be on the whole quite ignorant of the rational attitude which science could teach. Who would have predicted 28 years ago that the leaders of the main superpowers would continue their ever-accelerating and immensely costly weapons race, even though each side now has at its command the destructive power of 10,000 megatons, 10 billion tons, in a grotesque variety of nuclear arms. Both sides therefore have enough power to wage the equivalent of 6000 World War IIs, each one containing the horror of that war's tens of millions of deaths and its atomic bombs. Six thousand such wars; one every day for 17 years.

Perhaps because Bronowski had seen first-hand the devastation of the atomic bombs in Japan, he did not and could not have foreseen today's nightmare scenarios. $\mathrm{He}$ was guided by his faith in the rationalizing and civilizing power of the study of science, and his dislike of a "world run by specialists for the ignorant" [8] that would cause internal political dangers. $\mathrm{He}$ warned: "The scientists are inheriting, they are conquering the earth; and if you do not speak their uncouth language, then you will sink to the status of the native yokels when the Normans overran England. I have called my article 'The Educated Man' in order to warn of this danger" [9]. Bronowski risked a prediction, inspired by his fear of the ominous alternative: "It is certain that the educated man in 1984 will speak the language of science" [10]. For him, the only alternative to Orwell's 1984 was a society in which the statesman, the administrator, the humanist "is at home in the methods of science" [11]. 
Who would have thought in 1956 that the time would come when the statesman, the administrators and even some of the most influential scientists would be unable to count to 6000 and to conclude that enough is enough? One's mind would have rebelled against the prediction that in 1984 the world's peoples would be governed, with little protest, by essentially paranoid elites unable to take control of their genocidal and suicidal weapons. Members of the Politburo no doubt have had the regular education of Russian youths, with all its emphasis on physics, biology, calculus and so on. But this evidently does not translate into a sounder view of man and society, judging from Russia's continuing xenophobia and racism, not to speak of its lack of managerial skills. On this side of the ocean, the man who now shares the power over the final fate of mankind indicated his views about science by stating that the theory of evolution needs to be reconsidered in light of the claims of creationism; that his main interest in research and development is in their militarization; and in choosing as one of his most influential scientific advisors the so-called 'father of the H-bomb', who for a quarter of a century has urged the view that limited nuclear wars are not only thinkable but may give us more safety than no wars at all.

At this point I can see Bruno's bushy eyebrows shoot up. He might say, in his solemn and precise voice, "I admit that the timing in my prediction was off, but you and I fully agree on the desired state that must be reached sooner or later. And yet, when you say that a man of science, a brilliant physicist and one who has the ear of the president, has actually propagated the view you ascribe to him, you throw doubt on the fundamental proposition that the pursuit of science as such is rationalizing and civilizing. You'd better quote chapter and verse." And so I reply, "The essay in question is entitled "The Feasibility of Arms Control', the publication is Daedalus, the journal of the American Academy of Arts and Sciences, the date is fall 1960, the author is Edward Teller, and the passage reads as follows:

\footnotetext{
All-out war will never be in our interest, and we should never start it. If the Russians should want to embark on such a desperate enterprise, they will probably pick a time when our guard is down. While a limited nuclear war is in progrèss, we shall be much better prepared than in times of peace. The time of a limited nuclear conflict, therefore, would be the worst time for the Russians to launch an all-out attack. It is my belief that limited nuclear war can very well stay limited.
}

In fact, during the course of such a war, danger of an all-out war will be at a minimum [12].

The intervening decades have brought even more shocking evidence that hopes for the rationalizing power of science must be tempered by the facts. It is not irrelevant that in the U.S.A., the U.S.S.R. and most industrialized nations an estimated $30 \%$ of recent graduates in science and engineering now take jobs more or less connected to the research and development of weapons, in what Pope John Paul II recently called 'the laboratories and factories of death'.

Let me turn to the three other aspects of Bronowski's integrity of science. Starting with the most general and lofty interpretation of the phrase, Bronowski saw that science's power to instill integrity lay in the lesson that science's "habit of simple truth to experience has been the mover of civilization" [13]. This is why, in his essay on 1984 as in many others, he scorned "administrators and Greek scholars, boards of directors and doctors of divinity, bishops and generals" [14], among whom he found many who did not think "the scientist also has a share to contribute to culture, that humanism is doomed if it does not learn the living language, the springing thought of science" [15].

Bronowski did not defend the narrow benefits to science itself. On the contrary, he wrote, "My subject is science as part of culture, and scientific education as part of cultural education, because for lack of these life-giving parts the ancient cultures are dying at the roots" [16].

Thus, in The Identity of Man, Bronowski raised the question of how each individual can be part of nature and yet have confidence that he transcends nature-having in some sense immortality and uniqueness, being a self rather than, or at least as well as, a law-abiding machine, an automaton, or a giant computer. That humans are part of nature, "as is a stone or a camel or a cactus" [17], is a lesson of modern science. Initially this was a heresy, charged to pioneers stretching from Giordano Bruno to Darwin. Most of us now take for granted that there is no supernatural leap between the various parts of nature's creation, whether animal, vegetable or mineral. But when John Tyndall, as president of the British Association for the Advancement of Science, suggested this view about a century ago, proceedings were started against him in London for blasphemy.

But can there exist continuity with all of nature's creation, and also uniqueness for humans? Bronowski's answer was yes, and that again science pointed the way. Research in psychology, anthropology and the philosophy of science indicates that what is unique in humans is the nature of human knowledge. On the one hand, people differ from machines insofar as "the procedures for getting [human] experience cannot all be formalized" [18]. On the other hand, only human beings can deal with the essential ambiguities at the core of every complex scientific puzzle as well as in every artistic production.

Mankind's uniqueness in these respects provides, so to speak, the high hill in the middle of a plain, from which one can study the otherwise unbroken continuity of nature. Here we come to speak of the fourth element of Bronowski's thematic conception of the integrity of science: the underlying unity of scientific knowledge. With his usual eloquence, Bronowski explained:

\begin{abstract}
The most modest research worker at his bench, pushing a probe into a neuron to measure the electric response when a light is flashed, is enmeshed in a huge and intertwined network of theories that he carries into his work from the whole field of science, all the way from Ohm's law to Avogadro's number. He is not alone; he is sustained and held ... by the state of scientific theory in every branch. And what he finds is not a single fact either: it adds a thread to the network, ties a knot here and another there, and by these connections at once binds and enlarges the whole system [19].
\end{abstract}

Science, then, is not the sum of separate departments, as it is in a university where mathematics, physics, chemistry and biology each has a separate building. Rather Bronowski defended the concept that science is one organic interlocked picture of the world', an entity in which organic processes of actual research tie the parts together. Any substantial scientific research pursued in any one university building is likely to require a great deal of knowledge from specialties housed elsewhere. A modern paper on cosmology is a jigsaw puzzle of which the pieces might well be labeled 'elementary particle physics' and 'general relativity', 'applied mathematics', and 'observational astronomy'. An experiment in neurophysiology brings together physics, chemistry, biology, computer technology and engineering all at once.

The unity of science is an ideal dating back to Pythagoras, Thales and Democritus, a strong counter-theme to the tendency of many lesser individual scientists to lose themselves in narrow specialization. Today this ancient dream of the unity of science seems more alive 
than ever, both in the practice of research and in the results. To mention one indicator: at the turn of the century Nobel prizes tended to be awarded either to scientists who had found a previously unsuspected effect (such as X-rays or radioactivity) whose connection with the rest of nature nobody clearly understood, or to scientists who made precise measurements of isolated physical constants. But today the highest awards more often go to theorists who trace connections between the parts of nature's tapestry.

We now know, as Bronowski knew we would, that science grows rather like a sphere, expanding inside an inhomogeneous medium. The various specialized areas on the surface of the sphere handle the phenomena quite differently, each with its own specialized tools. These specializations are evident in the over 300,000 scientific journal articles published worldwide each year. But the results of these diverse encounters are processed and passed through the boundary to the inside of the sphere, where they are fitted together. In this way separate experiences, such as lightning and batteries and electric eels, were all subsumed many years ago under the single idea of electric current. Similarly, today thousands of different phenomena are explained by the electro-weak force. Bronowski wrote in "The Educated Man in 1984", "Science is not a set of facts but a way of giving order, and therefore of giving unity and intelligibility, to the facts of nature" [20]. This is why we think of the coherent structures in science as beautiful, for, as Bronowski quoted Coleridge, "Beauty is unity in variety".

The last of the five meanings of integrity implicit in Bronowski's work and thought is integrity in the moral sense. Bronowski stressed that science as an activity is not value neutral, but diffused with human values, as well as able to generate and change human values. His list of desiderata for increasing the chance of novel scientific findings-of reaping the fruits of the habit of truthruns like this: independence of character, originality of mind, freedom of thought and expression, tolerance of dissent, and high valuation both of change and of respect for the historic work on which present science must build. "Such are the first needs of science, and these are the values which of itself it demands and forms" [21].

Looking outward from the lab, science demands and imposes new values on the world. Looking inward, science also demands and imposes on itself a new morality. In closing, let me look at these two symmetrical notions, both embedded in Bronowski's writing, and both more at the forefront of discussion now than they were during Bronowski's time.

As to the first of these two meanings of integrity of science, i.e. in its moral sense, consider the huge impact of the advance of modern science and technology on our inherited conception of basic human rights. We are heading into ever more stormy ideological waters on issues such as the following: the perceived attacks on traditional values, owing to scientific findings and technical capabilities (for example, when does the so-called 'personhood' of an embryo start?; when should advanced technology for providing life support to the terminally ill be used and when not?); the role of technology with respect to privacy (increasing the potential, on the one hand, for its better protection, and, on the other hand, for its invasion); the contrary results of industrial innovation (automation versus greater unemployment; the increase of productivity versus the protection of occupational health); the defense of environmental purity versus the need to dispose of toxic effluents; the contrary roles of science and technology with respect to the issue of harm (for instance, the increase in the number of carcinogenic substances which the chemists create versus the huge increase in the accuracy with which we now detect the presence of potential carcinogens). And, again, with respect to war: new technology making new weapons more destructive, but also making agreements easier to monitor.

If considered case by case, as is usually done, such concerns appear unrelated to one another and indistinguishable from other political debates. But these cases are in fact at their foundations various versions of the same question: In a society that is being changed by science and technology, what are our proper human rights, our entitlements and our responsibilities? The roots of the modern Western position are the Mosaic Decalogue and the New Testament. But the first major modern thinker was Thomas Hobbes, who in Leviathan (1651) based his conception of the natural rights of man on the identification of life with mechanical motion, and the preservation of life with the preservation of motion. He took these notions from the scientific work of William Harvey and Galileo. Hobbes' classic list of a person's natural rights included "rights to govern his own body, to breathe, to drink, to eat, to come, to go", in short, to eat and be eaten. It has been a long way from Hobbes to the protective roles we now ask of the (U.S.) Environmental Protection Agency and the (U.S.) Federal Drug Administration, to the U.S. Supreme Court decision on abortion, to the Helsinki Accord. But Hobbes' thought was a launching in this direction.

Following Hobbes, John Locke, sometime intimate of and collaborator with Newton, helped formulate the classic theory of the rights of man, which comprised the natural rights-of life (including 'health', sustenance and other 'conveniences'), of liberty, and of property. Upon these notions were built the foundation we associate with Jefferson, Adams, Thomas Paine, the Virginia Declaration of Rights, the U.S. Constitution and the French Declarations of 1789 and 1793 (which added 'education' as a human right). Even since, there has been a steadily increasing stream of charters, covenants, declarations and international conventions. As the British scholar D.D. Raphael observed, twentieth-century declarations incorporate as necessities what in nineteenth-century declarations would have been luxuries, and the continuous expansion of the conception of need has been driven by material as well as moral advance. J.E.S. Fawcett, surveying the issue of the protection of human rights, concluded that "fundamental to all effective methods of implementation of human rights" is the development of scientific rationality itself, namely "independent and objective fact finding", as well as the modern technology of rapid communication.

Moreover, the increased abundance of resources resulting from advances in science and technology has vastly changed previous assumptions of possessive individualism, which were based on the notion of unavoidable, severe and global scarcity of resources. Historian Oscar Handlin has pointed out that one of the early, unexpected results of the new railway systems in nineteenth-century Europe was that with faster transportation local famines became unnecessary and hence intolerable. In analogous fashion, the existence at a nearby hospital of the computerized axial tomography (CAT) scan machine, nuclear magnetic resonance (NMR) scanner, kidney dialysis, and the triple bypass operation is apparently making access to these resources more and more a matter of basic universal entitlement. So is the assertion of the right of each woman to decide on her own body's reproductive activity - a veritable revolution in human rights since the advent of the birth control pill.

Recent developments from universities or industrial laboratories constantly challenge past assumptions of morals, ethics and human rights. Bronowski was 
an early pioneer in drawing attention to these issues, for example in his book Science and Human Values. Today a good portion of the United States' daily political and legislative activity could be filed under that heading.

Finally let us look in on the lab to see what science demands of itself. This topic is frequently in the news today, but Bronowski did not feel called upon to say much about it during his time. Perhaps he felt that internal ethics were adequately covered by the scientists themselves. To name only a few examples of the scientists' moral stands, one thinks of P.W. Bridgman, who in his Moratorium of 1939 closed his lab to visitors from the Axis nations; the 1945 manifestos of James Franck, Leo Szilard and colleagues, which asked that the atomic bomb not be dropped on civilians; Norbert Wiener's writings; the biomedical researchers who fashioned codes for experiments involving human and animal subjects; and, more recently, the Asilomar Conference and the science-and-ethics projects of the American Association for the Advancement of Science, the Federation of American Scientists (FAS) and other scientific organizations.

Nevertheless, some journalists in the United States have almost made it a specialty to pursue the idea that scientists on the whole are so blind to the integrity of science that they need the spur of external investigation. An example is a recent book by two journalists, entitled Betrayers of the Truth [22]. The book's subtitle is "Fraud and Deceit in the Halls of Science", and it opens with the simple and striking sentence, "This is a book about how science really works." The authors deride the idea that this large community-well over 600,000 scientists and engineers engaged in research and development in the U.S. alone-is remarkably effective in policing itself. The authors' expectations are very high indeed. "It requires only one case to surface every few months or so for the public credibility of science to be severely damaged."

The authors' assiduous research of the past two dozen years yielded 18 "known or suspected" cases of scientific fraud or deceit. Looking at these cases, one notes that except for the psychologist Cyril Burt, none of the accused could be considered distinguished researchers. Indeed, most were previously unknown and at the beginnings of their biomedical careers (I wonder why; perhaps it seems easier to paint a mouse than a quark).

Periodic exposés by the popular press of dark doings in the lab, even if only speculations or old cases resurrected, teach us chiefly that the public has an anxious interest in scientific fraud. Of course I agree that all cases of real fraud, even if rare, are to be condemned. But there is an easily neglected fact that is at least as important: the occasional report of fraud or error is only the dark side of a coin, the reverse side of which is entirely bright. The frontier of scientific research is in principle wide open, even to those who may turn out not to be sufficiently brought into the culture of science. The relatively minute number of documentable incidences of real abuse is a measure, a kind of an overhead cost, of the openness of the frontier and its hospitality to reports of new findings. If no abuse were to be found among the many hundreds of thousands of members of the whole scientific community, even once a year, it might well mean that the researchers were no longer saying anything new or unfamiliar. Science would then be an absolute system, 'fool proof', devoid of any ambiguity. Bronowski would have pointed out that such a system cannot work.

Moreover, passing all scientific work through some elaborate machinery of moral certification rather than using reasonable vigilance to catch the few would-be offenders could be very costly indeed, not least in its possible discouragement in recruiting the future Galileos, Newtons and their less-talented but equally prickly cousins. Then too, if more elaborate machinery should become necessary, I wonder who would set it up? Who would own and operate it? And what else would such a system be able and eager to provide? Let us not forget that there is always a strange crew waiting in the wings, anxious to set scientists and scholars aright and punish what they perceive to be mistakes and heresies. To name just two contenders, there are the creationists and, at the other end of the spectrum, people like the late philosopher Imre Lakatos who aimed to set up universal criteria for distinguishing between what he called 'progressive', as opposed to 'degenerating', research programs. One of his candidates for the degenerating research program was contemporary elementary particle physics. $\mathrm{He}$ offered his help to funding agencies and editors of scientific journals so they might reject "degenerating" work and "lay down statute law of rational appraisal which can direct a lay jury [for example, Congress] in passing judgment" [23]. Bronowski would have warned here: the fire in the stake is still smoldering, the stake on which all those are burned who run afoul of an absolutist system.

In summary, Bronowski saw and wrote about the integrity of science as made up of five elements. First, science must be an integral part of our personal tool kit of thought processes. Second, a society must incorporate the rationalizing power symbolized by scientific knowledge, for otherwise it will be a fatally split societysplit between a powerful elite and the disenfranchised mass. To this we add now: an irrational elite is the most dangerous of all.

Third, to avoid becoming petrified, a culture must allow the new findings of the sciences to refresh its old roots. Fourth, the purpose of science is to produce a connected conceptual whole rather than a catalogue of specialties. Fifth, science has a moral dimension, pointing on one side to the ascent of human rights and on the other to the way scientific work itself should be conducted.

Each of these propositions remains a lively issue today. On some of these our future as a society, as a culture, and even as a species depends. We can thank Jacob Bronowski for having put these issues before us so early and eloquently for our continuing thought and action.

\section{REFERENCES}

1. J. Bronowski, The Identity of Man (Garden City,, NY: The Doubleday/ Natural History Press, 1971) p. 16.

2. J. Bronowski, The Common Sense of Science (Cambridge, MA: Harvard Univ. Press, 1978); Science and Human Values (New York: Harper \& Row, 1956); The Ascent of Man (Boston: Little, Brown, 1974).

3. J. Bronowski, "The Educated Man in 1984". Science 123, 710-712 (1956).

4. Bronowski [3] p. 711.

5. Bronowski [3] p. 712.

6. Bronowski [3] p. 711.

7. Bronowski [3] p. 712.

8. Bronowski [3] p. 712.

9. Bronowski [3] p. 712 .

10. Bronowski [3] p. 712.

11. Bronowski [3] p. 712.

12. Edward Teller, "The Feasibility of Arms Control", Daedalus 794-795 (1960).

13. Bronowski, Science and Human Values [2] p. 58.

14. Bronowski [3] p. 710.

15. Bronowski [3] p. 710.

16. Bronowski [3] p. 710.

17. Bronowski [1] p. 3

18. Bronowski [1] p. 24

19. Bronowski [1] p. 46.

20. Bronowski [3] p. 710.

21. Bronowski, Science and Human Values [2] p. 80.

22. William Broad and Nicholas Wade, Betrayers of the Truth (New York: Simon \& Schuster, 1982).

23. Imre Lakatos, "Understanding Toulmin". Minerva 14, 128 (1976). 